\title{
Impacto de una técnica automatizada rápida en la identificación de SAMR/ERV en pacientes trasladados desde otros centros hospitalarios
}

\author{
Álvaro Rojas, Marcela Potin, Claudia Coria, Juan C. Román y Patricia García
}

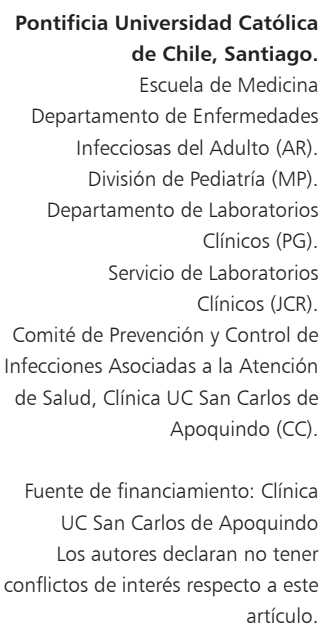

Fuente de financiamiento: Clínica UC San Carlos de Apoquindo

Los autores declaran no tener conflictos de interés respecto a este artículo.

Recibido: 20 de marzo de 2013 Aceptado: 3 de noviembre de 2013

Correspondencia a: Patricia García Cañete pgarcía@med.puc.cl

\section{Introducción}

A lgunas bacterias como Staphylococcus aureus resistente a meticilina (SARM) y Enterococus resistente a vancomicina (ERV), tienen un importante rol como agentes causales de infecciones asociadas a la atención de salud. Estas infecciones producen aproximadamente 90.000 muertes al año en Estados Unidos de América y se asocian con un exceso de costos de 4,5 billones de dólares ${ }^{1}$.

Por ello se han buscado distintas estrategias para reducir el impacto de estos agentes infecciosos en la práctica clínica. Dentro de estas estrategias destaca la vigilancia activa de la portación de bacterias multi-resistentes, a través de un hisopado nasal para SARM e hisopado rectal para ERV.

Históricamente se ha utilizado para la identificación de estos agentes el cultivo microbiológico tradicional. Sin embargo, esta metodología tiene una baja sensibilidad y requiere de la realización de estudios de susceptibilidad in vitro complementarios, lo que demora 3 a 5 días $^{2}$. Lo anterior, implica prolongar las medidas de precaución adicional de contacto, con el costo económico asociado y la mayor carga laboral para los trabajadores de salud que atienden al paciente.
Como una alternativa, se dispone actualmente de métodos de diagnóstico rápido por biología molecular, como la reacción de polimerasa en cadena (RPC), que facilitan la detección de bacterias resistentes directamente desde muestras clínicas. Éstas comprenden básicamente técnicas de RPC tradicional y RPC en tiempo real uno de los cuales es el sistema GeneXpert ${ }^{\mathrm{TM}}$ (Cepheid, Sunnyvale, CA), que permite en forma automatizada la extracción, amplificación y detección de cassette cromosomal mec (SCCmec) en Staphylococcus aureus ${ }^{3,4}$ y los genes de resistencia a vancomicina (vanA/vanB) en Enterococcus ${ }^{5,6,7}$. El ensayo CepheidXpert ${ }^{\mathrm{TM}}$ vanA/vanB que se realiza en el sistema GeneXpert ${ }^{\circledR} \mathrm{DX}$, es una prueba de diagnóstico in vitro cualitativa, diseñada para ser utilizada directamente en muestras rectales y perianales, en pacientes con riesgo de colonización intestinal por bacterias resistentes a vancomicina.

Este sistema automatizado es de fácil implementación y de baja complejidad en su uso cotidiano. Permite obtener resultados oportunos, en el plazo de una hora, luego de ser cargado con las muestras clínicas ${ }^{8}$. Ha sido validado en distintos escenarios clínicos, tanto para SARM ${ }^{5,9,10}$ como para $\mathrm{ERV}^{7,11}$. Las ventajas comparativas de estas técnicas son su rapidez en los resultados, el ser operador 
independiente, y su mayor rendimiento diagnóstico ${ }^{2}$. Se describe para GeneXpert MRSA ${ }^{\circledR}$ una sensibilidad, especificidad, valor predictor positivo y negativo de 90 , 97,86 y $98 \%$, respectivamente ${ }^{8}$. Del mismo modo, para GeneXpert VRE se ha reportado una sensibilidad, especificidad, valor predictor positivo y negativo de $96,4 \%$, 93, 92 y 96,9\%, respectivamente ${ }^{11}$.

La Clínica UC San Carlos de Apoquindo ubicada en el sector oriente de la Región Metropolitana, dispone de 105 camas, con 15 cupos para pacientes críticos adultos, y no presenta endemia para bacterias resistentes como SARM y ERV. Desde el año 2009 se observó un incremento de los traslados de pacientes desde otros centros de salud del país, tanto públicos como privados. Por esta razón, se decidió aplicar un protocolo de vigilancia de la portación de bacterias resistentes en el grupo de pacientes trasladados. En todos ellos se obtuvo muestras por hisopado nasofaríngeo e hisopado rectal y se indicó desde la admisión a la unidad, medidas de precaución adicional de contacto, las que se mantuvieron hasta disponer de resultados de cultivos negativos. Este método producía demoras de hasta 5 días en la suspensión de las precauciones de contacto, encareciendo los costos de hospitalización, generando incomodidad al paciente y complicando el trabajo del personal de salud. Por ello se decidió implementar una nueva técnica automatizada de RPC (GeneXpert $\left.{ }^{\mathrm{TM}}\right)$, para detectar colonización por SARM y ERV en pacientes trasladados de otros centros hospitalarios. Se diseñó este estudio con el objeto de evaluar el impacto de este nuevo método en los tiempos de respuesta y costos.

\section{Materiales y Métodos}

Se evaluó la portación de bacterias resistentes: SARM (muestra nasal) y ERV (muestra rectal), en pacientes adultos trasladados desde otros centros hospitalarios a Clínica UC San Carlos de Apoquindo en dos períodos: el primero entre junio y diciembre de 2009 y el segundo entre junio y diciembre de 2010.

Durante el primer período se empleó el método tradicional (cultivo aeróbico) para la búsqueda de ERV, consistente en la siembra de las muestras de hisopado rectal en agar selectivo enterococcosel ${ }^{\circledR}$ (BBL, BectonDickinson, USA) y posterior incubación por toda la noche a $35^{\circ} \mathrm{C}$. $\mathrm{Al}$ día siguiente, las colonias negras se traspasaron a una placa de agar cromogénico VRE (chromID ${ }^{\circledR}$, bioMerieux, Marcyl'Etoile, Francia) y nuevamente se incubaron toda la noche a $35^{\circ} \mathrm{C}$. Si había desarrollo de colonias moradas se emitía un informe parcial Enterococcus faecium screening positivo para resistencia a vancomicina y se realizaba el estudio de susceptibilidad por epsilometría-Etest ${ }^{\circledR}$ (bioMerieux, Marcyl'Etoile, Francia) para vancomicina. Para la búsqueda de SARM, las muestras de hisopado nasal fueron sembradas en agar sangre de cordero (bioMerieux,
Marcy 1 'Etoile, Francia) y las colonias morfológicamente sugerentes eran identificadas por la prueba de la coagulasa en tubo y susceptibilidad a vancomicina por dilución en agar.

En el segundo período se utilizó RPC en tiempo real a través de sistema GeneXpert ${ }^{\mathrm{TM}}$ (Cepheid, Sunnyvale, CA), que había sido previamente verificado a partir de muestras de pacientes positivos y negativos para ERV y SARM. Brevemente, la metodología para ERV consiste en insertar el hisopo con la muestra del paciente en el reactivo de dilución y se agita por 10 segundos, se deja reposar 3 min y luego se transfiere todo el contenido al compartimento de ensayo del cartucho. Posteriormente se agrega el reactivo 1 (Buffer Tris, EDTA y surfactante) al compartimento 1 del cartucho y el reactivo 2 (hidróxido de sodio) al compartimento 2 del mismo y se introduce el cartucho en el equipo Genexpert. El procesamiento para SAMR es similar con la diferencia de que no se agregan los reactivos 1 y 2 .

Se obtuvieron muestras nasales y rectales por medio de dos hisopos estériles al momento del ingreso. Éstas fueron cargadas en cartuchos, de uso único, para la identificación de SAMR y ERV, obteniendo resultados dentro de una hora. Este módulo se encontraba localizado en el laboratorio de Microbiología de Red Salud UC, a una distancia de $25 \mathrm{~km}$ por lo que las muestras fueron enviadas, según protocolo institucional a dicho laboratorio para su análisis.

De acuerdo al protocolo de traslado de pacientes desde otros centros hospitalarios, se procedió a instaurar precaución de contacto, para todos los pacientes trasladados a Clínica UC San Carlos de Apoquindo en ambos períodos estudiados. Esta medida se mantuvo activa hasta disponer del resultado de la vigilancia de la portación de SARM y ERV. La precaución de contacto incluía el uso de pechera de manga larga y guantes, señalética adecuada y limitación del desplazamiento del paciente fuera de la unidad.

Se incluyeron pacientes trasladados a la unidad de paciente crítico, que comprende servicios de intensivo, intermedio y unidad coronaria y la unidad médico quirúrgica de la clínica. Los pacientes se encontraban en pieza individual, salvo los que estaban en el servicio de intensivo (cuatro camas), los que compartían un espacio físico común, pero con una separación de más de un metro entre camas.

Se registraron variables demográficas de los pacientes trasladados, origen de los traslados y la unidad de ingreso a esta clínica. También se registraron resultados de vigilancia de portación de SARM y ERV, tiempo hasta obtener dicho resultado, duración total de la precaución de contacto y costos asociados a estas medidas.

Se analizaron las variables categóricas con test de chicuadrado y las continuas fueron analizadas con t-student. Se consideró p significativo $<0,05$. Se utilizó software SPSS 15.0 para el análisis estadístico. 
Tabla 1. Resultados en grupo estándar y grupo RPC

\begin{tabular}{|c|c|c|}
\hline & $\begin{array}{l}\text { Grupo estándar } \\
\qquad n=167\end{array}$ & $\begin{array}{c}\text { Grupo RPC } \\
n=87\end{array}$ \\
\hline Edad promedio (años) & $55 \pm 20$ & $61 \pm 19$ \\
\hline Sexo masculino (\%) & $53 \%$ & $54 \%$ \\
\hline Traslado desde sistema público (\%) & $61,7 \%$ & $35,6 \%$ \\
\hline Positividad global & $16 / 167(9,6 \%)$ & $26 / 87(29,9 \%)$ \\
\hline Positividad SARM & 10/167 (6\%) & $13 / 87(14,9 \%)$ \\
\hline Positividad ERV & $11 / 167(6,6 \%)$ & $15 / 87(17,2 \%)$ \\
\hline Tiempo de respuesta (h) & $53 \pm 23^{*}$ & $15 \pm 9^{*}$ \\
\hline Duración precaución (días) & $4 \pm 1^{*}$ & $2 \pm 1 *$ \\
\hline
\end{tabular}

Tabla 2. Costos en USD de insumos y exámenes en grupo estándar y grupo RPC

$\begin{array}{lcc}\text { Insumos/exámenes } & \begin{array}{c}\text { Costos grupo estándar } \\ \text { USD }\end{array} & \begin{array}{c}\text { Costos grupo PCR } \\ \text { USD }\end{array} \\ \text { Tórulas de transporte }(\times 2) & 1,8 & 1,8 \\ \text { Cultivo tradicional SAMR }(\times 1) & 12,8 & -- \\ \text { Cultivo tradicional ERV }(\times 1) & 16,7 & --- \\ \text { Pecheras } & 242 & 69 \\ \text { Guantes } & 12 & 3,4 \\ \text { PCR para ERV y SAMR } & --- & 171 \\ \text { Total } & 530^{*} & 245^{*}\end{array}$

*Estimación en base a número de contactos por paciente: 110 pares de guantes y 110 pecheras/día. Cálculo en base a uso de pecheras y guantes por un promedio de $53 \mathrm{~h}$ en grupo estándar versus $15 \mathrm{~h}$ en grupo PCR. Valor unitario 0,05 USD por par de guantes y 1 USD por pechera. ${ }^{* *} p<0,05$.

\section{Resultados}

\section{Grupo estándar}

Durante el período junio-diciembre de 2009 se identificaron 167 pacientes trasladados desde otros centros hospitalarios, en los que se obtuvo muestra nasal y rectal por hisopado. Sus características se observan en la Tabla 1.

Un 79,6\% (n: 133) de los pacientes, ingresó a la unidad de pacientes críticos. Se confirmó que 9,6\% (n: 16) de los pacientes tenían cultivos de vigilancia positivo para una o más de las bacterias multi-resistentes estudiadas. $\mathrm{Al}$ analizar por agente infeccioso, $6 \%$ (n: 10) correspondió a pacientes con portación de SARM y 6,6\% (n: 11) a ERV.

\section{Grupo RPC}

Durante el período junio-diciembre de 2010 se identificaron 87 pacientes trasladados. Respecto al centro hospitalario de origen de estos pacientes, $35,6 \%$ (n: 31 ), provenía de hospitales del servicio público nacional. El $79,6 \%$ de los pacientes ingresó a unidad de cuidados intensivos de la clínica. En el grupo RPC se identificó 29,9\% (n: 26) de pacientes portadores de agentes multiresistentes. Al analizar por agente infeccioso, en 14,9\% (n: 13) se confirmó SARM y 17,2\% (n: 15) ERV. Ambas cifras fueron superiores, con significación estadística $(p<0,05)$, en comparación con el grupo estándar.

En relación a los tiempos de respuesta de los resultados microbiológicos, en el grupo RPC, $(15 \pm 9 \mathrm{~h})$, éstos fueron inferiores en relación al grupo estándar $(53 \pm 23 \mathrm{~h})$ con un $\mathrm{p}<0,05$. La duración total de las medidas de precaución de contacto fue de $4 \pm 1$ día en grupo estándar y de $2 \pm 1$ día en el grupo RPC $(p<0,05)$ (Tabla 1$)$.

Al analizar los costos directos relacionados con la implementación de precauciones de contacto durante el estudio, éste ascendió a USD 530 por paciente en el grupo estándar y a USD 245 por paciente en el grupo RPC $(\mathrm{p}<0,05)$ (Tabla 2).

Los costos de los exámenes fueron asumidos por la clínica según el procedimiento vigente.

No se consideraron costos de traslado puesto que las muestras de ambos grupos debieron ser transportadas al mismo laboratorio para su procesamiento.

\section{Discusión}

La implementación de una técnica rápida y automatizada (RPC en tiempo real) para la detección de microorganismos multi-resistentes (SAMR y ERV) en pacientes trasladados a Clínica UC San Carlos, aumentó la detección de casos de 9,6\% obtenido con cultivos tradicionales, a $29,6 \%$ con técnica RPC. Esto podría estar asociado a una mayor sensibilidad del método RPC, descrita en la literatura científica ${ }^{11}$; el estudio no fue diseñado, sin embargo, para evaluar sensibilidad de la técnica.

El estudio permitió demostrar una reducción en los tiempos de espera de resultados de laboratorio y con ello, de la duración de las precauciones de contacto en los pacientes cuyos resultados eran negativos.

Considerando que la realización de la técnica de RPC demora alrededor de una hora, los plazos descritos, son aún muy prolongados, lo que es explicable porque en esa etapa fue necesario trasladar las muestras a otro laboratorio de la red salud de la Pontificia Universidad Católica. Considerando esto, a partir del segundo semestre del año 2011, se implementó la técnica en el laboratorio dentro de la clínica, con lo que se logró una mayor reducción de los tiempos. Así mismo, los costos fueron también reducidos al acortar los tiempos de uso de implementos de precaución de contacto y evitar el traslado de muestras fuera de la clínica.

Una limitación de este estudio, es que no se evaluó 
ambas técnicas en forma simultánea, sino secuencial, lo que pudo introducir un sesgo, por variaciones en la complejidad de los pacientes y con ello, del riesgo de portación de microorganismos multi-resistentes. Para reducir este efecto, se compararon períodos similares de dos años sucesivos (junio a diciembre). En ambos períodos la proporción de pacientes que ingresó a UCI fue similar (79,6\% en ambos grupos). En el segundo período, la proporción de pacientes trasladados desde el sistema público fue menor, aunque no significativo, debido a variaciones en los convenios de gestión de camas de la clínica.

Otro aspecto que no fue analizado, es la percepción de los pacientes y la familia sobre las mejoras en el nuevo procedimiento. Esto es relevante, puesto que el uso de precauciones de contacto y otras medidas de aislamiento puede reducir los tiempos de contacto del personal clínico y puede favorecer la sensación de aislamiento. Si bien esto debe ser evaluado, es probable que la nueva metodología, sea bien aceptada por ellos, y que los haga sentir menos aislados y estigmatizados.

Tampoco fue un objetivo el evaluar la precepción del personal de salud sobre el uso de la nueva técnica; sin embargo, es probable que ésta facilite su labor al acortar las precauciones de contacto y aislamientos.

La implementación de este sistema automatizado en el contexto de un protocolo de manejo de pacientes trasladados tuvo un alto impacto en el manejo clínico y en los costos.

En resumen, la RPC en tiempo real GeneXpert para detectar portación de SAMR y ERV constituye una valiosa herramienta clínica, por cuanto es de fácil implementación, entrega resultados en menor tiempo y reduce el tiempo de precauciones de contacto así como los costos asociados. Los resultados de este estudio justifican la incorporación rutinaria de esta nueva técnica.

\section{Resumen}

Introducción: La identificación de pacientes con Staphylococcus aureus resistente a meticilina (SARM) y Enterococcus resistente a vancomicina (ERV), permite limitar su diseminación usando aislamiento en cohorte y precauciones de contacto. Los resultados de los cultivos microbiológicos demoran 3 a 5 días, lo que retrasa el retiro de las precauciones y agrega costos económicos. Objetivos: Implementar técnica de reacción de polimerasa en cadena en tiempo real (RPC), GeneXpert R, para SARM y ERV y comparar tiempos de respuesta y costos en relación al uso de microbiología convencional. Material y Métodos: Se compararon dos períodos, uno en que se usó solo RPC (grupo RPC) y otro histórico, en el que se usó microbiología tradicional (grupo estándar) Resultados: Se confirmó SARM y/o ERV en 29,9\% de los pacientes del grupo RPC, y en 9,6\% del grupo estándar. Los tiempos de respuesta fueron $15 \pm 9 \mathrm{~h}$ (grupo RCP) y $53 \pm 23 \mathrm{~h}$ (grupo estándar). Los costos directos por paciente fueron de USD 245 en el grupo RPC y de USD 530 en el grupo estándar. Discusión: La RPC en tiempo real, GeneXpert, para SAMR y ERV tuvo un alto impacto alto clínico que justifica su incorporación.

\section{Referencias bibliográficas}

1.- Edwards J R, Peterson K D, Andrus M L, Tolson J S, Goulding J S, Dudeck M A, et al and NHSN facilities. National Healthcare Safety Network (NHSN) Report, data summary for 2006, issued June 2007. Am J Infect Control 2007; 35: 290-301

2.- Harbarth S, Hawkey P M, Tenover F, Stefani S, Pantosti A, Struelens M J. Update on screening and clinical diagnosis of methicillin resistant Staphylococcus aureus (MRSA). Int J Antimicrob Agents 2011; 37: 110-7.

3.- Ulrich M P, Christensen D R, Coyne S R, Craw P D, Henchal E A, Sakai S H, et al. Evaluation of the Cepheid GeneXpert system for detection of Bacillus anthracis. J Appl Microbiol 2006; 100: 1011-6.

4.- Gavino M, Wang E. A comparison of a new real-time polymerase chain reaction system to traditional culture in determining group $\mathrm{B}$ streptococci colonization. Am J Obstet Gynecol 2007; 197: 388e1-4.
5.- Kelley P G, Grabsch E A, Howdwn B P, Gao W, Grayson M L. Comparison of the Xpert MRSA assay, BD GeneOhm MRSA assay and culture for the detection of nasal and cutaneous groin colonization by methicillin resistant Staphylococcus aureus (MRSA). J Clin Microbiol 2009; 47: 3769-72.

6.- Parta M, Goebel M, Matloobi M, Stager C, Musher D M. Identification of methicillin resistant or methicillin susceptible Staphylococcus aureus in blood cultures and wound swabs by GeneXpert. J Clin Microbiol 2009; 41: 1609-10.

7.- Bourdon N, Berenger R, Lepoultier R, Mouet A, Lesteven C, Borgey F, et al. Rapid detection of vancomycin resistant enterococci from rectal swabs by the Cepheid XpertvanA/vanB assay. Diag Microb Infect Dis 67: 291-3

8.- Rossney A S, Herra C M, Brennan G I, Morgan P M, O'Connell B. 2008. Evaluation of the Xpert methicillin-resistant Staphylococcus aureus (MRSA) assay using the GeneXpert real-time PCR platform for rapid detection of MRSA from screening specimens. J Clin Microbiol 2010; 46: 3285-90.

9.- Wolk D M, Picton E, Johnson D, Davis T, Pancholi P, Ginocchio C C, et al. Multicenter evaluation of the Cepheid Xpert methicillinresistant Staphylococcus aureus (MRSA) test as a rapid screening method for detection of MRSA in nares. J Clin Microbiol 2009; 47: 758-64.

10.- Malhotra-Kumar S, Van Heirstraeten L, Lee A, Abrahantes J C, Lammens C, Vanhommerig E, et al. Evaluation of molecular assays for rapid detection of methicillin-resistant Staphylococcus aureus. J Clin Microbiol 2010; 48: 4598-601.

11.- Marner E, Wolk D, Carr J, Hewitt C, Domínguez L, Kovacs T, et al. Diagnostic accuracy of the Cepheid GeneXpertvanA/ vanB assay ver 1.0 to detect the $\operatorname{van} \mathrm{A}$ and $\operatorname{van} \mathrm{B}$ vancomycin resistance genes in Enterococcus from perianal specimens. Diag Microbiol Infect Dis 2011; 69: 382-9. 